\title{
Commentary
}

\section{Let's get back to work: Preventive biological cycle management of COVID-19 in the workplace}

\author{
Mehdi Jahangiri ${ }^{\mathrm{a}}$, Rosanna Cousins ${ }^{\mathrm{b}}$ and Vahid Gharibi ${ }^{\mathrm{c}, \mathrm{d}, *}$ \\ ${ }^{a}$ Department of Occupational Health, School of Health, Shiraz University of Medical Sciences, Shiraz, Iran; \\ ORCID ID 0000-0002-4703-2523 \\ ${ }^{\mathrm{b}}$ Department of Psychology, Liverpool Hope University, Liverpool, UK; ORCID: 0000-0003-4829-5138 \\ ${ }^{c}$ Department of Occupational Health, School of Health, Shiraz University of Medical Sciences, Shiraz, Iran; \\ ORCID: 0000-0002-9974-3060 \\ ${ }^{\mathrm{d}}$ Department of Occupational Health, School of Public Health, Shahroud University of Medical Sciences, \\ Shahroud, Iran; ORCID: 0000-0002-9974-3060
}

Received 13 June 2020

Accepted 23 June 2020

\begin{abstract}
.
BACKGROUND: The primary response to the coronavirus (COVID-19) pandemic has been to minimize social contact through lockdown measures. The closure of non-essential businesses to tackle the spread of the coronavirus has had negative consequences for the global economy, production, and employment.

OBJECTIVE: To outline how known occupational health principles can be used for preventative management of the coronavirus in workplaces to support resumption of work.

METHODS: A discussion of current knowledge of COVID-19, the cost of the lockdown strategy, and preventative biological cycle management.

RESULTS: The evidence-based literature indicates that biological cycle management can control the risk of coronavirus infection, provide a suitable and sufficient exit strategy from lockdown, and support getting employees back to work. Adherence to personal protective equipment standards has been insufficient, indicating a need for workplace investment and education.

CONCLUSION: Imposed restrictions on workplace operations can be lifted without compromising worker health and safety when a workplace commits to practicing the three principles of biological cycle management.
\end{abstract}

Keywords: Lockdown, COVID-19, biological hazard, risk assessment, personal protective equipment (PPE)

\section{Introduction}

Occupational health is considered as the art and science of predicting, identifying, assessing, and

*Address for correspondence: Vahid Gharibi, Department of Occupational Health, School of Health, Shiraz University of Medical Sciences, Shiraz, Iran. E-mail: gharibivahid@gmail.com. controlling hazardous agents in workplaces [1]. Hazardous agents that may threaten an employee's health include chemical (gases, vapors, metals, etc.), physical (ionizing and non-ionizing beams, noise, etc.), and biological agents (viruses, fungi, bacteria). From this position, it must be realized that SARS-CoV-2, commonly known as the new coronavirus, is a biological agent that could be present in the workplace. 
Information from the World Health Organization affirms that the coronavirus is highly infectious. It spreads through the air on the back of increased coughing or sneezing, and even talking and breathing; transmission occurs through physical contact with respiratory secretions both directly and indirectly from contact with an infected surface. The new coronavirus is highly contagious to the extent that within six months of emerging from China at the end of 2019 it had reached almost every country in the world. To date, over eight million people are known to have caught COVID-19, the disease caused by the coronavirus, and the recorded global death toll by June 2020 was approaching half a million people. Whilst COVID-19 may not have a fatal trajectory for all, the illness, and the ease of spread in itself has been significant in precipitating emergency measures of quarantine, social distancing and lockdown. In the absence of a vaccine or efficient medication, stay-at-home orders have been strictly enforced in many countries. Unless one is employed in providing essential services or supplying basic necessities, the lockdown has led to working at home, or not at all.

It has become clear that there are costs as well as benefits for tight lockdown; decision making is complicated and influenced by culture and politics [2]. Disease models clearly demonstrate that lockdown controls delay time to infection of a population [2], the fraction of the population that would have been infected should lockdown not have been put in place dissipates over time [3], and the estimated loss of $8 \%$ of annual gross domestic product for keeping lock down tight for one month has to be weighed against health and welfare costs of managing serious infection and death which could be as much as three times higher [3]. All of this evidence, however, does not take into account that a period of time when no work is done as a consequence of lockdown can be fatal to an organization, and lead to sustained loss of employment. There have been substantial job losses as a result of the coronavirus pandemic in the US [4] and in every population affected [5]. Unemployment, particularly in times of high unemployment, is detrimental to physical and mental health [6]. The impact of the coronavirus crisis on work has differed according to industry. About a third of employees can work from home $[7,8]$ which has served to mitigate some of the economic and health sequelae of lockdown; nevertheless stay-at-home measures are not sustainable [9], hence the call for exit strategies from lockdown whilst accepting that health risks from the coronavirus will remain until a safe vaccine is available. An effective release from lockdown to get back to work in this context requires a full understanding of the risk situation.

\section{Proactive or reactive approach?}

Whilst the coronavirus is a new hazard, it remains a biological hazard; thus, known risk management principles should be drawn upon to support safe and healthy work. Preventative approaches in the field of occupational safety and health can be drawn upon to effectively implement control measures to preserve employee health [10]. Potentials for exposure can be predicted, risks of harm to employees (and service-users) can be identified, and as far as is reasonably practicable, they can be prevented by adopting known infection controls measures [1]. Rim and Lim [11] presented a comprehensive review of protection against biological factors in many working scenarios; risk assessment, use of personal protective equipment (PPE), thorough cleaning, ventilation, proper waste management and disposal, as well as information, instruction, training and supervision are required. For many workplaces, this is a small extension of previous practices, but should be afforded.

Gharibi et al. [12] found that managers of industries and healthcare authorities adopt two types of approach to deal with workplace hazards: they either proactively prevent incidents, or they operate in reaction to an incident. Despite legal imperatives in almost all countries to risk assess to control workplace hazards, upfront costs and lack of sufficient enforcement can lead to reactive measures being the norm because of deficiencies in enforcement of Health \& Safety legislation. Nevertheless, to manage work in the context of dynamic biological agents such as the coronavirus, reactive approaches that only deal with hazards when they have become crises will ultimately escalate to harm to the health of both employees and organization.

We reiterate, the coronavirus is a hazard, however, just like other workplace hazards, the risk of harm from the coronavirus can be controlled using a proactive approach; adopting proven scientific and practical measures. The value of quarantines, thorough handwashing, use of PPE, and social distancing as practical measures to ameliorate the potentials of the coronavirus have been well documented elsewhere. We note them here as a component of a proactive intervention strategy to use to support work in the situation where the coronavirus remains 
a severe risk to life and health. PPE, sufficient washrooms, a rigorous cleaning regime, and social distancing are proven practical measures that can be put in place to manage the coronavirus to permit safe return to work. Assuming managers can proactively ensure suitable and sufficient PPE is provided to all employees, and they can set out an occupational environment that does not allow unprotected personal contact, then risk of COVID-19 is minimized in the workplace.

Considering these issues, for an organization to return to work, a proactive approach with clear steps to ameliorate potentials for infection is essential, coupled with assurance for managers and employees that a suitable proactive approach to cope with the coronavirus is being implemented.

\section{Biological cycle management}

Viruses spread through person-to-person contact. For the coronavirus, this can be insidious contact. Infection occurs when someone breathes in these respiratory droplets, or touches a surface where they have fallen, then touches their face. In addition, unlike physical hazards or chemical hazards, harm from biological hazards is not swift. While estimates of the incubation period of the coronavirus vary, analyses from passengers on the Diamond Princess cruise ship hosting 3,711 passengers enabled reliable statistical modelling indicating it could be some 5.5 to 9.5 days [13] before appearance of the raised temperature and constant cough that serve as the primary symptoms of the COVID-19 disease status. Similarly, Lauer et al. [14] collected evidence from 181 confirmed cases with known exposure and symptom development to report than median onset was 5.1 days. They were also able to estimate that development of symptoms of COVID-19 will be within 11.5 days of exposure for $97.5 \%$ of people, providing confidence in the rule of 14 days of self-isolation after known contact with an infected person. Understanding this biological cycle is considered as the main point in the preventative management of the coronavirus in the workplace.

An organization taking full advantage of the proactive biological cycle management approach will keep employees safe from COVID-19 by interrupting the viral biological cycle. This is critical whilst there is currently no vaccine and no definitive treatment for COVID-19. Essentially, the program of viral biological cycle management comprises three important principles: self-care, other-care, and self-quarantine.
Education at work can support compliance with the principles.

\subsection{Principle of self-care}

Self-care is regarded as a measure in which each individual uses their awareness, knowledge, skills, and capability to care for their own health. This includes knowing the signs and symptoms of COVID19 , and full participation in personal preventative measures (e.g. respiratory etiquette, social distancing, wearing PPE as situations dictate, handwashing, cleaning surfaces).

\subsection{Principle of other-care}

Other-care is similar to self-care with the difference that individuals care for their colleagues, along with care for self. Basically, when individuals operate in ways that prevent the spread of the coronavirus in the workplace, they use their awareness, knowledge, skills, and capability to protects the health of colleagues.

\subsection{Principle of self-quarantine}

Self-quarantine means that employees stay at home when they have any of the primary symptoms of COVID-19. Additionally, the principle of selfquarantine is suggested for those working alongside a colleague who develops symptoms indicative of COVID-19. Self-quarantine is an important measure to prevent the spread of disease among other staff and their families.

\section{Conclusion}

The coronavirus pandemic has put a large part of the world's economy into lockdown. Whilst there are opportunities for some employees to work at home, many cannot. Many businesses and their employees want an exit strategy and to get back to their workplace with confidence that their health status will not be compromised. Proactive occupational principles, appropriately put in place, will support work and prevent coronavirus infection. Identifying hazards and implementing biological cycle management, as we have outlined, with provide an exit strategy for getting back to work even whilst the coronavirus remains a biological hazard. 


\section{Conflict of interest}

The authors declare that there is no conflict of interest.

\section{Funding}

This research received no specific grant from any funding agency in the public, commercial, or not-forprofit sectors.

\section{References}

[1] Jayjock MA, Lynch J, Nelson DI. Risk assessment principles for the industrial hygienist: American Industrial Hygiene Association, US. 2000. ISBN-13:978-09326 27971

[2] Tellis GJ, Sood N, Sood A. Did the US governors delay lockdown against COVID-19? Disease science vs learning, cascades, and political polarization. USC Marshall School of Business Research Paper. Available at http://ssrn.com/ abstract $=3575004$

[3] Alvarez F, Argente D, Lippi F. A simple planning problem for Covid-19 lockdown. Covid Economics. 2020;14:1-32.

[4] Coibion O, Gorodnichenko Y, Weber M. Labor markets during the Covid-19 crisis: a prelimiary view. CESifi Working Paper No 8238; 2020. ISSN 2364-1428.
[5] Ozili P, Arun T. Spillover of COVID-19: impact on the global economy. MPRA Paper No. 99850; 2020. Available at https://mpra.ub.uni-muenchen.de/99850/

[6] Drydakis, N. The effect on unemployment on self-reported health and mental health in Greece from 2008 to 2013: a longitudinal study before and during the financial crisis. Soc Sci Med. 2015;128:43-51.

[7] Dingel JI, Neiman B. How many jobs can be done at home? BFI White Paper, Becker Friedman Institute 2020.

[8] Pennington A, Stanford J. Working from Home: Opportunities and Risks. Sydney: Centre for Future Work 2020.

[9] Gilbert M, Dewatripont M, Muraille E, Platteau J-P, Goldman M. Preparing for a responsible lockdown exit strategy. Nature Medicine. 2020;26:643-4.

[10] Gharibi V, Cousins R, Jahangiri M. Coronavirus-related opportunities for promoting occupational health \& safety. SEMJ. 2020;e104655.

[11] Rim K-T, Lim C-H. Biologically hazardous agents at work and efforts to protect workers' health: a review of recent reports. Safety Health Work. 2014;5:43-52.

[12] Gharibi V, Mokarami H, Cousins R, Jahangiri M, Eskandari D. Excessive Daytime Sleepiness and Safety Performance: Comparing Proactive and Reactive Approaches. Int J Occup Environ Med. 2020;11(2):95-107.

[13] Mizumoto K, Katsushi K, Alexander Z, Gerado C. Estimating the asymptomatic proportion of coronavirus disease 2019 (COVID-19) cases on board the Diamond Princess cruiseship, Yokohama, Jampan, 2020. Euro Surveill. 2000;25(10):pii=2000180.

[14] Lauer SA, Grantz KH, Bi Q, Jones FK, Zheng Q, Meredith HR, Azman AS, Reich NG, Lessler J. The incubation period of coronavirus disease 2019 (COVID-19) from publicly reported confirmed cases: estimation and application. Ann Intern Med. 2020;172(9):577-82. 